\title{
Off-pump or on-pump coronary artery bypass grafting in diabetes: Is this the important question?
}

\author{
Chaim Locker, MD
}

\author{
From the Department of Cardiovascular Surgery, Mayo Clinic, Rochester, Minn. \\ Disclosures: Author has nothing to disclose with regard to commercial support. \\ Received for publication Aug 28, 2018; accepted for publication Aug 28, 2018; available ahead of print Oct 12, \\ 2018. \\ Address for reprints: Chaim Locker, MD, Department of Cardiovascular Surgery, Mayo Clinic, 200 First St SW, \\ Rochester MN 55905 (E-mail: lekerlocker.chaim@mayo.edu). \\ J Thorac Cardiovasc Surg 2019;157:970-1 \\ $0022-5223 / \$ 36.00$ \\ Copyright (c) 2018 by The American Association for Thoracic Surgery \\ https://doi.org/10.1016/j.jtcvs.2018.08.069
}

Diabetes mellitus is an epidemic, affecting millions of patients in the United States and worldwide, and its prevalence is constantly rising. Nearly $50 \%$ of patients currently undergoing coronary artery bypass grafting (CABG) have diabetes. Survival after $\mathrm{CABG}$ among patients with diabetes is considerably worse, ${ }^{1}$ mainly because of the severity of coronary disease, the inferior response to current myocardial revascularization methods, and the multiorgan impact of the disease. Any investigation seeking to define the treatments in this group of patients is therefore of vast importance.

In this issue of the Journal, Huang and colleagues ${ }^{2}$ present their analysis of the outcomes of 13,441 patients with diabetes who underwent isolated CABG between 2000 and 2011, with data derived from the National Health Insurance Database in Taiwan. Of those patients, 9341 were operated on with the use of cardiopulmonary bypass (onpump group); the remaining 4100 were operated on with the off-pump technique. Huang and colleagues ${ }^{2}$ were able to match 3796 patients in each group, and the median follow-up time was 5.4 years. They concluded that at 30 days and at 1 year after the operation, the on-pump group had significantly higher mortalities than those of the offpump group (hazard ratio, 1.52; and hazard ratio, 1.50, respectively); however, both techniques had similar longterm event-free rates at 10 years for mortality, stroke, and myocardial infarction. Long-term repeat revascularization rates were substantially higher in the off-pump group, and there was a significant survival benefit in patients with end-stage renal disease operated on with cardiopulmonary bypass (hazard ratio, 0.68).

A strength of this report is the large cohort of patients with diabetes, more than the combined number included in 3 recent randomized trials, the Randomized On/Off Bypass trial (ROOBY), ${ }^{3}$ the CABG Off or On-Pump Revascularization study (CORONARY), ${ }^{4}$ and the Off-Pump versus On-Pump Coronary-Artery Bypass Grafting in Elderly Patients trial (GOPCABE). ${ }^{5}$ Another strength is that the analysis is based on a comprehensive national

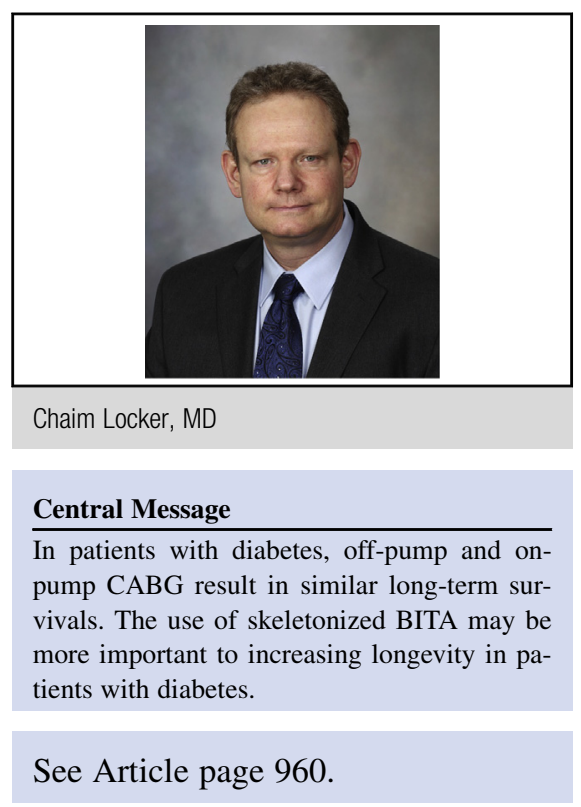

database. This report could have been the ideal setup to obtain significant results that could clarify some of the current on-pump versus off-pump CABG controversies, especially after the recent publication of the 5-year outcomes of the ROOBY trial, which showed that off-pump CABG led to increased mortalities and lower 5-year event-free survival relative to on-pump $\mathrm{CABG}^{6}$

Unfortunately, the study of Huang and colleagues ${ }^{2}$ suffers from some shortcomings. First, we did not receive data about how experienced the surgeons involved in this study were in performing off-pump CABG, other than the inclusion of a variable in the propensity matching of "hospital volume of CABG" and the statement that a majority of cases $(65 \%)$ were performed in high-volume centers $(>200$ CABG cases/y overall). Importantly, the major criticism about the ROOBY trial was the perceived high conversion rate from off-pump to on-pump CABG (12.4\%), which was more than 3.4 times as high as the reported rate in the Society of Thoracic Surgeons database. It appears that this initially presented value was an intention-to-treat crossover rate, however, and the ROOBY authors ${ }^{7}$ recalculated it to $6.3 \%$, which is lower than that reported in the CORONARY study $(7.9 \%)^{8}$

The high conversion rates implied another argument, that the surgeons participating in the ROOBY trial were relatively inexperienced in off-pump surgery, and that this 
inexperience resulted in the inferior off-pump outcomes observed. The GOPCABE trial, on the other hand, showed no differences in major adverse cardiac and cerebrovascular events between on-pump and off-pump CABG at 1 year, nor did the CORONARY trial show any differences at 1- and 5-year follow-up. ${ }^{9}$ These outcomes only partially support the study findings of Huang and colleagues. ${ }^{2}$

Perhaps more importantly, in the study of Huang and colleagues $^{2}$ we were not presented with any details about the surgical technique and conduits used. The use of skeletonized bilateral internal thoracic artery (BITA) is crucial in patients with diabetes. Raza and colleagues ${ }^{10}$ reported outcomes of 11,922 patients with diabetes undergoing CABG and showed that the largest impact observed was that of the use of BITA, which increased the 20-year survival by $21 \%$, followed by completeness of revascularization $(10 \%)$. Again, there was no marked difference found in 10-year survival between the off-pump and on-pump groups. ${ }^{10}$ In addition, the perception that graft patency is inferior in patients with diabetes has been recently questioned by an analysis showing that the 20-year patency rate of BITA was greater than $90 \%$, that vein graft patency was declining to approximately $40 \%$, and that those rates were similar for patients both with and without diabetes. ${ }^{11}$ These findings amplify the argument in favor of increasing the use of skeletonized BITA in CABG overall, and specifically in patients with diabetes. With the notion that the rates of both off-pump CABG $(>60 \%)$ and arterial grafting in Asian countries are much higher than those in Western countries,${ }^{12}$ the missing data regarding BITA use per group in the study of Huang and colleagues ${ }^{2}$ are even more important.

There should be a consensus that the goal of every CABG operation is the appropriate selection and harvest of conduits $^{13}$ and the completeness of revascularization, rather than the avoidance of cardiopulmonary bypass. These goals apply even more in patients with diabetes. The only exception would be in the case of a porcelain aorta, in which case the avoidance of cardiopulmonary bypass and aortic manipulation would be prudent. ${ }^{14}$ Future investigations are warranted to define better who could benefit from off-pump surgery. It seems that a change in the manner of tailoring and analyzing trials is also necessary. ${ }^{15}$

\section{References}

1. Raza S, Sabik JF III, Ainkaran P, Blackstone EH. Coronary artery bypass grafting in diabetics: a growing health care cost crisis. J Thorac Cardiovasc Surg. 2015; 150:304-12.

2. Huang KC, Wu IH, Chou NK, Yang YY, Lin LC, Yu HY, et al. Late outcomes of off-pump versus on- pump coronary bypass in diabetic patients: a nationwide study from Taiwan. J Thorac Cardiovasc Surg. 2019;157:960-9.

3. Shroyer AL, Grover FL, Hattler B, Collins JF, McDonal GO, Kozora E, et al. Veterans Affairs Randomized On/Off Bypass (ROOBY) Study Group. On-pump versus off-pump coronary-artery bypass surgery. N Engl J Med. 2009;361: 1827-37.

4. Lamy A, Deveraux PJ, Prabhakaran D, Taggart DP, Hu S, Paolasso E, et al; CORONARY Investigators. Effects of off-pump and on-pump coronary-artery bypass grafting at 1 year. N Engl J Med. 2013;368:1179-88.

5. Diegler A, Börgermann J, Kappert U, Breuer M, Böning A, Ursulescu A, et al; GOPCABE Study Group. Off-pump versus on-pump coronary-artery bypass grafting in elderly patients. N Engl J Med. 2013;368:1189-98.

6. Shroyer AL, Hattler B, Wagner TH, Collins JF, Baltz JH, Quin JA, et al; Veterans Affairs ROOBY-FS Group. Five-year outcomes after on-pump and off-pump coronary-artery bypass. N Engl J Med. 2017;377:623-32.

7. Shroyer AL, Hattler B, Grover FL. Five-year outcomes after on-pump and offpump coronary-artery bypass. $N$ Engl J Med. 2017;377:1898-9.

8. Stevens LM, Noiseux N, Avezum A, Aypati DR, Chen X, Lucchese FA, et al; CORONARY Investigators. Conversion after off-pump coronary artery bypass grafting: the CORONARY trial experience. Eur J Cardiothorac Surg. 2017;51: 539-46.

9. Lamy AL, Deveraux PJ, Prabhakaran D, Taggart DP, Hu S, Straka Z, et al; CORONARY Investigators. Five -year outcomes after off-pump or on-pump coronaryartery bypass grafting. $N$ Engl J Med. 2016;375:2359-68.

10. Raza S, Sabik JF III, Masabni K, Ainkaran P, Lytle BW, Blackstone EH. Surgical revascularization techniques that minimize surgical risk and maximize late survival after coronary artery bypass grafting in patients with diabetes mellitus. J Thorac Cardiovasc Surg. 2014;148:1257-66.

11. Raza S, Blackstone EH, Houghtaling PL, Rajeswaran J, Riaz H, Bakaeen FG et al. Influence of diabetes on long-term coronary artery bypass graft patency. J Am Coll Cardiol. 2017;70:515-24.

12. Park SJ, Ahn JM, Kim YH, Park DW, Yun SC, Lee JY, et al; BEST Trial Investigators. Trial of everolimus-eluting stents or bypass surgery for coronary disease. N Engl J Med. 2015:372:1204-12.

13. Locker $\mathrm{C}$. To skeletonize the internal thoracic artery or not to skeletonize? To be or not to be! J Thorac Cardiovasc Surg. 2018;155:229-31.

14. Zhao DF, Edelman JJ, Seco M, Bannon PG, Wilson MK, Byrom MJ, et al. Coronary artery bypass grafting with and without manipulation of the ascending aorta. a network meta-analysis. J Am Coll Cardiol. 2017;69: 924-36.

15. Noiseux N, Stevens LM, Chartrand-Lefebvre C, Soulez G, Prieto I, Basile F, et al CORONARY Investigators. Off-pump versus on-pump coronary artery bypass surgery: graft patency assessment with coronary computed tomographic angiography. A prospective multicenter randomized controlled pilot study. J Thorac Imaging. 2017;32:370-7. 